\title{
The Sorcerer's Apprentice: Sleeping Sickness, Onchocerciasis and Unintended Consequences in the Gold Coast and Ghana, 1930-60 - ADDENDUM
}

David Bannister

Published online by Cambridge University Press: 12 April 2021 doi:10.1017/S0021853721000177

The author regrets the omission of the financial support details in the above article.

The information is provided below and the article has been updated.

Financial Support. This research was funded by the Arts and Humanities Research Council (Doctoral Grant No. 1351945), and was supported by the European Research Council (Project No. 759820 - 'Universal Health Coverage and the Public Good in Africa').

\section{Reference}

Bannister, D. (2021). The Sorcerer's Apprentice: Sleeping Sickness, Onchocerciasis, And Unintended Consequences In Ghana, 1930-60. The Journal of African History, 62(1), 29-57. 